\title{
Prevalence and factors associated with modern contraceptive discontinuation among reproductive age group women, a community based cross-sectional study in Humera town, northern Ethiopia
}

Nigisti Belete ${ }^{1}$, Ayalnesh Zemene ${ }^{2}$, Hadgay Hagos $^{3}$ and Abere Yekoye ${ }^{3^{*}}$

\begin{abstract}
Background: Contraceptive prevalence rate (CPR) for married women aged 15-49 in Ethiopia is 36\%, with 35\% using modern methods and $1 \%$ using traditional methods. However, the discontinuation rate is fairly high. Women usually discontinue contraception use for fertility and method related reasons without adopting an alternate method which in turn leads to many health risks such as unwanted pregnancy, unplanned childbearing, miscarriage, abortion, leads to morbidity and mortality among mothers and newborns. The purpose of this study was to determine the prevalence of modern contraceptive discontinuation and to identify predicting factors.

Methods: A community- based cross- sectional study was conducted in Humera town among 321 married women of reproductive age (15-49 yrs.) who had a history of modern contraceptive use. Systematic sampling technique was employed to select study participants and data was collected by BSc health extension workers using interviewer-administered questionnaire. EPI-INFO (V-7) and SPSS (V-23) software were used for entry and analysis respectively. Descriptive statistics and logistic regression analysis were used to present results accordingly. P-Value $\leq 0.05$ was used as a cut point for statistical significance.

Results: The magnitude of modern contraceptive discontinuation was $27.1 \%$. Number of desired children $(A O R=2$. $8395 \% \mathrm{Cl}=1.16,6.89)$, experience of side effects ( $A O R=395 \% \mathrm{Cl}=1.2,7.58)$, discussion with female friend ( $A O R=$ $3.2695 \% \mathrm{Cl}=1.27,8.36)$, counseled on side effects ( $\mathrm{AOR}=6.5595 \% \mathrm{Cl}=2.21,19.39$ ), number of male children (AOR $=2.5195 \% \mathrm{Cl}=1.06,5.96)$, absence of husband support ( $\mathrm{AOR}=12.9995 \% \mathrm{Cl}=4.59,36.78)$ and presence of community prohibition ( $\mathrm{AOR}=6.8895 \% \mathrm{Cl}=3.05,15.51$ ) were identified as predicting factors for modern contraceptive discontinuation.
\end{abstract}

Conclusion: Magnitude of modern contraceptive discontinuation among reproductive age group women in Humera was relatively high. Increasing community awareness, involving partners and pre dispensation counseling might help to reduce discontinuation and its consequences. Various targeted messages are also needed to dispel misconception at community level.

Keywords: Humera, Modern contraceptive, Discontinuation, Reproductive age women

\footnotetext{
* Correspondence: abe2004g@gmail.com

${ }^{3}$ Department of Midwifery, Mekelle University College of health Sciences,

Mekelle, Ethiopia

Full list of author information is available at the end of the article
}

(c) The Author(s). 2018 Open Access This article is distributed under the terms of the Creative Commons Attribution 4.0 International License (http://creativecommons.org/licenses/by/4.0/), which permits unrestricted use, distribution, and reproduction in any medium, provided you give appropriate credit to the original author(s) and the source, provide a link to the Creative Commons license, and indicate if changes were made. The Creative Commons Public Domain Dedication waiver (http://creativecommons.org/publicdomain/zero/1.0/) applies to the data made available in this article, unless otherwise stated. 


\section{Background}

Contraceptive discontinuation, measured as the percentage of currently married women who used a method of contraception in the past but were not using a method at the time of data collection. The discontinuation rates are highest in sub-Saharan Africa where the majority of women in 13 of 18 countries have discontinued using contraception. In countries outside of sub- Saharan Africa, the discontinuation rates vary between 19 and 36\% [1].

Demographic and health survey (DHS) reports of different countries on contraceptive discontinuation, reasons, challenges, and solutions among married women 15-49 shows 12-month discontinuation rates were in Kenya 36\%, Zimbabwe 17.7\%, Armenia 30.6\%, Egypt 32\% and Colombia $43.8 \%$ [2]. Literatures report different reasons (method and fertility related) and factors to discontinue specific methods, where the major factors reported include: Age of participants, parity, family size, having television and radios, decision maker to use modern contraceptive (MC), partner supports, perceived benefit to the family, perceived $\mathrm{MC}$ harm, duration of contraceptive use, counseling, desired number of children and type of contraceptive were associated with contraception discontinuation [3-7].

In Ethiopia, use of any contraceptive methods among married women has increased nearly six-fold in the last 20 years, the increase in contraceptive use is especially pronounced for the use of modern methods. Overall, $36 \%$ of married women are using a method of family planning; $35 \%$ are using $\mathrm{MC}$ and $1 \%$ are using a traditional method. Despite all this, the discontinuation rate for all methods is $37 \%[5,6]$.

Moreover; women discontinue using modern methods without adopting alternate method for different reasons and this usually leads to many undesirable health risks such as unwanted pregnancy, unwanted or unplanned childbearing, miscarriage, abortion, morbidity and mortality among mothers, newborns or both [7], but knowing the magnitude and predicting factors will help to reduce the burden of these consequences. In addition, very little is known about the prevalence and associated factors modern contraceptive discontinuation (MCD) in Ethiopia in general and no data in the study area in particular. Therefore, this paper aims to have certain contribution in closing this gap.

\section{Methods}

\section{Study area and study period}

This study was conducted from 1 to 30 Feb 2017 G.C in Humera Town; Western Tigray, Ethiopia. Humera is located at $991 \mathrm{~km}$, North-West from Addis Ababa and $580 \mathrm{~km}$ western from Mekelle. According to the 2007 Census, the total population of the town is about 34,295 and approximately half of the inhabitants are younger than 20 years old. The town has one general hospital (Kahsay Abera Hospital), one health center (Setit primary health center) and 6 private clinics to serve this population. The health service coverage of the town is $100 \%$ and $62 \%$ contraceptive prevalence rate.

\section{Study design and sampling}

The study design was community-based cross-sectional study. The sample size was calculated using single population proportion formula with the following assumptions: The proportion of women who discontinued contraception in Agarfa District (25.5\%) (23), 95\% confidence level and $5 \%$ margin of error. The minimum desired sample with this assumption was 292 . By adding $10 \%$ non-response rate, a total of 321 study participants were included in the study.

\section{Sampling technique}

Systematic sampling was used to select study participants. All four kebeles were included and the total number households $(\mathrm{HH})$ of source population in each kebele were identified by number in advance. Then, the final sample size (321) was proportionally allocated to the number of households identified. Finally; women from each kebele were included in the study by systematic sampling technique using a sampling interval of 10 units. The first sample to be included was identified using lottery method. When two or more eligible women were present in one household, only one woman was considered by lottery method.

\section{Data collection}

After reviewing different literatures; properly designed semi-structured questionnaire containing both close and open ended questions was developed in English to collect the data. The questionnaire contained a total of 38 questions and designed to collect data concerning sociodemographics (17 questions), fertility related factors (8 questions) and method related factors (13 questions). Data was collected for a period of 1 month by home to home visit using face to face interview. Four BSc health extension workers and two BSc midwives were involved in the data collection process as data collectors and supervisors respectively.

The quality of data maintained through the following measures: Translation of questionnaire to the local language, training of data collectors and supervisors on the purpose of the study and data collection process, close supervision and prompt feedback, revision of completed data every day, conducting pre-test before data collection.

\section{Data management and analysis}

Data was checked for completeness, the corresponding code number was written carefully at each margin. Data was entered and cleaned with EPI Info version 7 then exported to SPSS (V-23) for analysis. Modern contraceptive discontinuation has been defined as women who used condom, OCP, injectable, implants and IUCD 
contraception method in the past 5 years but were not using a method at the time of the survey [6].

Descriptive statistics such as mean (and median for skewed distribution) and quartiles were used to assess the general characteristics of participants and their current modern contraceptive status. Binary logistic regression was used to show crude association among dependent and independent variables. Finally, multiple logistic regression analysis was used to analyze the influences of socioeconomic, fertility and method related factors on modern contraceptive discontinuation by controlling confounding factors. Results were presented using text, figures and tables accordingly. $P$-value of $\leq$ 0.05 was considered to determine statistical significance for both binary and multiple logistic regression.

\section{Results}

Socio-demographic and economic characteristics

This study was conducted among 321 married reproductive age women and the response rate was $100 \%$. The

Table 1 Socio-demographic and economic characteristics of participants, in Humera town, 2017 ( $n=321$ )

\begin{tabular}{|c|c|c|c|}
\hline Variables & Category & $\mathrm{N}$ & Percent \\
\hline \multirow[t]{4}{*}{ Participants religion } & Orthodox & 283 & $88.2 \%$ \\
\hline & Muslim & 28 & $8.7 \%$ \\
\hline & Protestant & 7 & $2.2 \%$ \\
\hline & Catholic & 3 & $0.9 \%$ \\
\hline \multirow[t]{4}{*}{ Participants age (yr.) } & $<=24$ & 53 & $16.5 \%$ \\
\hline & $25-29$ & 119 & $37.1 \%$ \\
\hline & $30-34$ & 80 & $24.9 \%$ \\
\hline & $>35$ & 69 & $21.5 \%$ \\
\hline \multirow[t]{5}{*}{ Educational status } & Not able to read and write & 25 & $7.8 \%$ \\
\hline & Able to read and write & 48 & $15.0 \%$ \\
\hline & Primary school (1-8) & 167 & $52.0 \%$ \\
\hline & Secondary school (9-12) & 66 & $20.6 \%$ \\
\hline & College and above & 15 & $4.7 \%$ \\
\hline \multirow[t]{3}{*}{ Occupation } & Housewife & 228 & $71.0 \%$ \\
\hline & Government employee & 24 & $7.5 \%$ \\
\hline & Self-employee & 69 & $21.5 \%$ \\
\hline \multirow[t]{5}{*}{ Husband educational level } & Not able to read and write & 23 & $7.2 \%$ \\
\hline & Able to read and write & 31 & $9.7 \%$ \\
\hline & Primary school (1-8) & 167 & $52.0 \%$ \\
\hline & Secondary school (9-12) & 67 & $20.9 \%$ \\
\hline & College and above & 33 & $10.3 \%$ \\
\hline \multirow[t]{4}{*}{ Husband occupation } & Government employee & 54 & $16.8 \%$ \\
\hline & Self-employed & 129 & $40.2 \%$ \\
\hline & Farmer & 135 & $42.1 \%$ \\
\hline & Others $^{a}$ & 3 & $0.9 \%$ \\
\hline \multirow[t]{5}{*}{ Mothers monthly income } & No income & 228 & $71 \%$ \\
\hline & $<=499$ birr & 18 & $5.6 \%$ \\
\hline & 500-999 birr & 11 & $3.4 \%$ \\
\hline & 1000-1499birr & 8 & $2.5 \%$ \\
\hline & $>=1500$ birr & 56 & $17.5 \%$ \\
\hline \multirow[t]{4}{*}{ Husband monthly income } & $<=499$ birr & 16 & $5.0 \%$ \\
\hline & 500-999 birr & 11 & $3.4 \%$ \\
\hline & 1000-1499birr & 21 & $6.5 \%$ \\
\hline & $>=1500$ birr & 273 & $85.0 \%$ \\
\hline
\end{tabular}


mean age of participants was 29.6 years $(\mathrm{SD} \pm 5.6)$, where above one third of participants 119(37\%), were in the age group between 25 and 29 years. Most of the participants $283(88.2 \%)$ were Orthodox by religion and $\mathrm{Ti}$ gray $251(78.2 \%)$ by ethnicity. Nearly three fourth of the participants $228(71 \%)$ were housewives, and nearly half $135(42 \%)$ of their partners were farmers by occupation.

Majority of the participants 307(95.6\%) were living with their husbands but the rest $14(4.4 \%)$ were not, and $19(5.9 \%)$ of participants reported that their husband had another wife, where one third $6(31.6 \%)$ had two another wives. Majority of the participants $278(86.6 \%)$ were discussed with their female friends on $\mathrm{MC}$ and about $284(88.5 \%)$ stated the presence of husband support to use MC. Most of the participants 275(85.7\%) reported they have television and nearly half $123(38.3 \%)$ have a radio in their home (Table 1 ).

\section{Reproductive characteristics}

Age at first marriage range was from 11 to 27 years with the mean age of 18.6 years $(S D \pm 2.74)$. Majority of the participants 298 (92.8\%) reported that they had an experience of giving birth and at first birth was 20 years $(\mathrm{SD} \pm 2.6)$ which ranges from 15 to 30 years. The average number of children per household was two (2.18) children $(\mathrm{SD} \pm 1.4)$.

Regarding desire to have additional children, of those who had experience of birth, 195(65.4\%) reported that their husbands need to have additional children. Moreover, the number of desired children ranges from one child to seven children with an average of nearly four (3.87) children per household. Decision on the number of children mostly made by both husband and wife 286(89.1\%), husband alone 24(7.48\%), wife alone $10(3.12 \%)$ and other family members $1(0.31 \%)$.

\section{Prevalence of modern contraceptive discontinuation}

The prevalence of modern contraceptive discontinuation was $27.1 \%$ ( $95 \% \mathrm{CI}=22.24,31.96)$. Of those participants included in this study 234 (72.9\%) were on modern

Table 2 Variability of MC discontinuation by type of MC, among participants in Humera town, 2017( $n=321)$

\begin{tabular}{llll}
\hline & \multicolumn{2}{l}{ Current status of MC use } & Total \\
\cline { 2 - 3 } & Yes & No & \\
\hline Type of MC used & & $1(25 \%)$ & 4 \\
Condom & $3(75 \%)$ & $6(37.5 \%)$ & 16 \\
OCP & $10(62.5 \%)$ & $60(30.9 \%)$ & 194 \\
Injectable & $134(68.3 \%)$ & $19(19 \%)$ & 100 \\
Implant & $81(81 \%)$ & $1(14.3 \%)$ & 7 \\
IUCD & $6(85.7 \%)$ & 87 & 321 \\
Total & 234 & & \\
\hline
\end{tabular}

Table 3 Variability of MC discontinuation by the duration of MC use, among participants in Humera town, 2017( $n=321)$

\begin{tabular}{llll}
\hline & \multicolumn{2}{l}{ Current status of MC use } & Total \\
\cline { 2 - 3 } & Yes & No & \\
\hline Duration of MC use & & $11(40.7 \%)$ & 27 \\
$<=6$ month & $16(59.3 \%)$ & $15(27.8 \%)$ & 54 \\
$7-12$ month & $39(72.2 \%)$ & $61(25.4 \%)$ & 240 \\
$>=13$ month & $179(74.6 \%)$ & 87 & 321 \\
Total & 234 & & \\
\hline
\end{tabular}

contraceptive use during the interview time. Among the major MC methods, the highest discontinuation was for the OCP users (37.5\%), and in contrast IUCD had the lowest discontinuation (14.3\%) (Table 2).

The median duration of use before stopping the method was $27(\mathrm{IQR}=27)$ months with minimum 1 and maximum 156 months. The discontinuation rate decreases with increase in duration of contraceptive use. The chances of discontinuation of modern contraceptive use are higher (40.7\%) in the initial 1-6 months period and chances to dropout decrease to $27.8 \%$ during $7-12$ months period (Table 3).

Above half 58(66.7\%) of the participants stated that want to get pregnant was their main reason for not currently using $\mathrm{MC}$ followed by experience of side effect 17(19.5\%) (Table 4).

Among those who experience side effects of MC (234), $73(31.1 \%)$ of participants discontinued using modern contraception. The most frequently reported side effect was menstrual irregularity $(41.6 \%)$ followed by weight gain (34.7\%) (Fig. 1).

All most all 319(99.4\%) of participants had access to all type of modern contraceptive (MC). Of all participants, 319(99.4\%) were utilizing the type of MC that they prefer to use and similarly most participants 292(91\%) were counseled on side effects of contraceptive. Almost all 320(99.7\%) participants reported that using $\mathrm{MC}$ has health benefits and 7(2.2\%) of participants have stated that $\mathrm{MC}$ is harmful to the womb. Fifty five $(17.1 \%)$ of the participants stated that there are things that prohibit them from using $\mathrm{MC}$ in their community.

Table 4 Reasons for MC discontinuation, among participants in Humera town, $2017(n=87)$

\begin{tabular}{lll}
\hline Reasons for MC discontinuation & Frequency(n) & Percent (\%) \\
\hline To get pregnant & 58 & $66.7 \%$ \\
Side effect & 17 & $19.5 \%$ \\
Partner disapproval & 11 & $12.6 \%$ \\
Bad rumors & 11 & $12.6 \%$ \\
Others $^{\mathrm{a}}$ & 9 & $10.3 \%$
\end{tabular}

${ }^{a}$ fear of infertility, being menopause, to use other than MC, perceives MC is sinful 


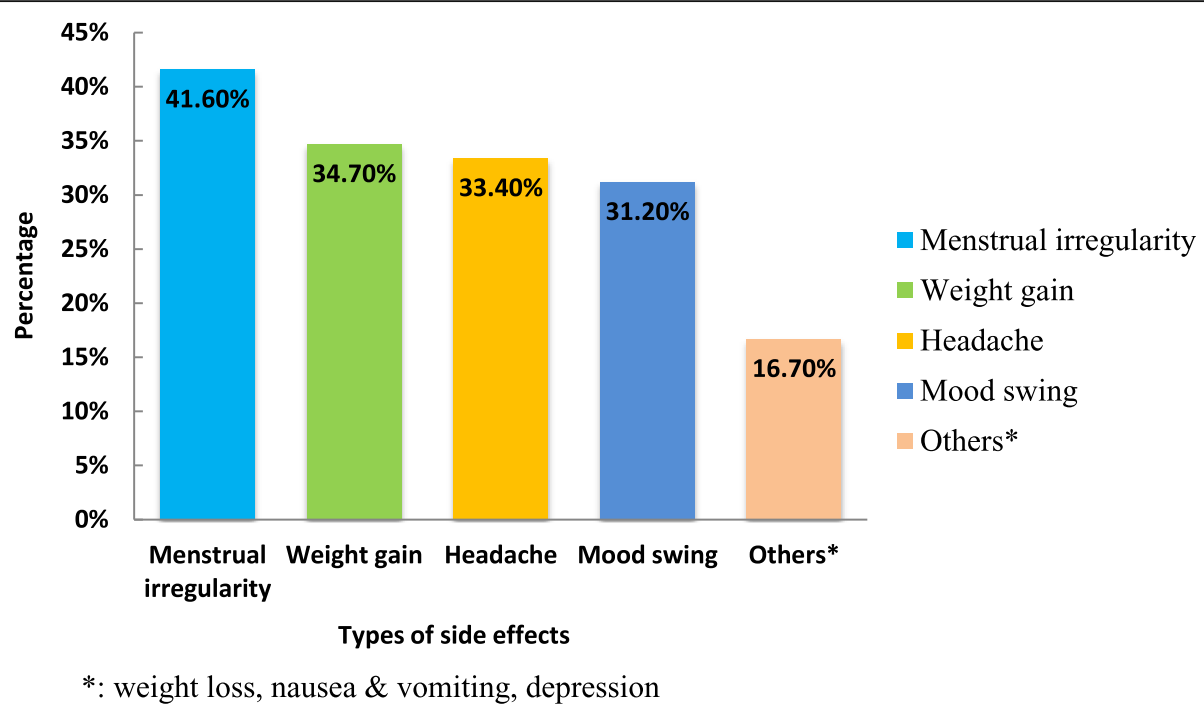

Fig. 1 MC side effects experienced by participants in Humera town, $2017(n=234)$. Types of side effects $(\%)$ reported by women who experienced side effects of modern contraceptive method (234) analyzed using multiple response sets

\section{Factors associated with modern contraceptive} discontinuation

On multiple logistic regressions analysis; experience of side effect $(\mathrm{AOR}=3.01 \mathrm{CI}=1.2,7.58)$, not discussing on $\mathrm{MC}$ with female friend $(\mathrm{AOR}=3.26 \mathrm{CI}=1.27$, 8.36), not counseled on side effects $(\mathrm{AOR}=6.55 \mathrm{CI}=$ $2.21,19.39)$, haven't had husband support to use $\mathrm{MC}$ $(\mathrm{AOR}=12.99 \mathrm{CI}=4.59,36.78)$ community prohibition to use $\mathrm{MC}(\mathrm{AOR}=6.88 \mathrm{CI}=3.05,15.51)$, having less than two male children $(\mathrm{AOR}=2.51 \mathrm{CI}=1.06,5.96)$ and desired number of children $(\mathrm{AOR}=2.83 \mathrm{CI}=$ $1.16,6.89)$ were found to be predictors at $\leq 0.05$ $p$-value significance level (Table 5).

\section{Discussion}

This study was conducted to assess discontinuation of modern contraception among married women of reproductive age group who live in Humera town, North Ethiopia. In this study, the prevalence of $\mathrm{MC}$ discontinuation among married women who had a history of MC use within 5 years at the time of survey was $27.1 \%$ with a median duration of 27 months. This is consistent with other studies conducted in Peshawar (27.5\%) and Agarfa (25.5\%) districts [3, 8]. This similarity might be due to the fact that these studies conducted in a specific community and the educational level of most study participants were primary schools and above. On the other hand, this finding is lower than study findings in Bangladesh (36\%), Philippines (37.2\%), Colombia (43\%), Kenya (33-36\%) and Ethiopia (37.1\%) [6, 9-11]. This could be because of different reasons; one and main reason might be due to the study period, as the current contraceptive use service has improved compared to other studies. The other possible reason might be the study population; the studies done in the countries mentioned above were done at national level with high sample size and included both rural and urban participants.

In this study we asked participants reason for MCD. Above half $(66.7 \%)$ of discontinuers stated that desire to get pregnant was their main reason for not using MC followed by experience of side effect (19.5\%) and partner disapproval (12.6\%). Similar reasons for discontinuation were reported by studies done in Agarfa, Ethiopia and Bangladesh [3, 11]. Contrary to this other studies reported different reasons: in Ofla district, Tigray, Ethiopia; health concern (46.2\%), want more children (43.6\%) and side effect (35.9\%), in Philippines method failure (14\%), side effects $(6.2 \%)$ and to get pregnant (5.6\%) and in Peshawar health concern (45.5\%), side effect (40\%) and wanted more children $(34.5 \%)[8,9,12]$. This difference with a study in Ofla district might be due to different population characteristics since it was done in a district as compared to this study which is done in a town. On the other hand, the difference with a study done in Philippines and Peshawar could be because they are developed country and may be more aware of MC use.

Our findings concerning factors associated with modern contraceptive discontinuation generally corroborate with previous research. This study shows that desire to have four or more children increase odd of modern contraceptive discontinuation [13]. In line to this; a study done in Armenia reported that odds of 
Table 5 Multivariate analyses of selected factors affecting MC discontinuation among married women in the reproductive age group, Humera town, $2017(n=321)$

\begin{tabular}{|c|c|c|c|c|c|}
\hline \multirow[t]{2}{*}{ Variables } & \multicolumn{2}{|c|}{ Current status of MC use } & \multirow[t]{2}{*}{ COR $(95 \% \mathrm{Cl})$} & \multirow[t]{2}{*}{ AOR $(95 \% \mathrm{Cl})$} & \multirow{2}{*}{$\begin{array}{l}P \text { - } \\
\text { value }\end{array}$} \\
\hline & Yes & No & & & \\
\hline \multicolumn{6}{|c|}{ Husband wants to have an additional child } \\
\hline Yes & 138 & 57 & $2.62(1.38,4.99)$ & $1.26(.50,3.19)$ & 0.62 \\
\hline No & 89 & 14 & 1 & 1 & \\
\hline \multicolumn{6}{|c|}{ Using implant type of MC } \\
\hline Yes & 82 & 19 & $.52(029, .92)$ & $0.77(.36,1.67)$ & 0.51 \\
\hline No & 152 & 68 & 1 & 1 & \\
\hline \multicolumn{6}{|c|}{ Number of desired children } \\
\hline$<=3$ & 91 & 19 & 1 & 1 & \\
\hline$>=4$ & 143 & 68 & $2.28(1.28,4.04)$ & $2.83(1.16,6.89)$ & $0.02^{*}$ \\
\hline \multicolumn{6}{|c|}{ Experience of side effects } \\
\hline Yes & 161 & 73 & $2.36(1.25,4.46)$ & $3.01(1.2,7.58)$ & $0.01^{*}$ \\
\hline No & 73 & 14 & 1 & 1 & \\
\hline \multicolumn{6}{|c|}{ Discussion on MC with a female friend } \\
\hline Yes & 214 & 64 & 1 & 1 & \\
\hline No & 20 & 23 & $3.84(1.98,7.44)$ & $3.26(1.27,8.36)$ & $0.01^{*}$ \\
\hline \multicolumn{6}{|c|}{ Counseled on side effects } \\
\hline Yes & 226 & 66 & 1 & 1 & \\
\hline No & 8 & 21 & $8.98(3.81,21.22)$ & $6.55(2.21,19.39)$ & $0.00^{*}$ \\
\hline \multicolumn{6}{|c|}{ Number of alive male children } \\
\hline 0-1 male & 148 & 57 & $2.17(1.14,4.14)$ & $2.51(1.06,5.96)$ & $0.03^{*}$ \\
\hline$>=2$ males & 79 & 14 & 1 & 1 & \\
\hline \multicolumn{6}{|c|}{ Husband support to use MC } \\
\hline Yes & 226 & 58 & 1 & 1 & \\
\hline No & 8 & 29 & $14.12(6.13,32.53)$ & $12.99(4.59,36.78)$ & $0.00^{*}$ \\
\hline \multicolumn{6}{|c|}{ Presence of community prohibition } \\
\hline Yes & 20 & 35 & $7.20(3.84,13.48)$ & $6.88(3.05,15.51)$ & $0.00^{*}$ \\
\hline No & 214 & 52 & 1 & 1 & \\
\hline
\end{tabular}

*Statistical significant at $P$-value $\leq 0.05$

discontinuation increase nearly two times if a women's number of live children were four or more as compared to women who had less than four children [14] and in Agarfa district for a single increase in family size the likelihood of MC discontinuation decreases by $12 \%$ [3].

This study identified that not having male child or having only one alive male child increase the chance of modern contraceptive discontinuation, which is a new finding identified only in this study. This might be due to wrong community perception still there is a gap in believing gender equality, that is why even though they have more children but they want to have a male child.

This study also found that experiencing contraceptive side effects as one of the major reason for contraceptive discontinuation and experience of contraceptive side effect of particular contraceptive method was found to be strongly associated with MCD that increase the chance of discontinuation by three fold. Consistent to this finding a study in Peshawar reported that women who experience side effects were eight times more likely to discontinue using contraception [8] and in Ofla, Tigray, Ethiopia; where women who have experienced side effects after insertion of Implanon were 2.8 times more likely to discontinue as compared to women who didn't [12]. One and main reason might be due to poor pre dispensation counseling on the commonly happened side effects and strategies for method mix or switching in case of experiencing a side effect. 
Improving quality of contraceptive counseling is one strategy to decrease contraceptive discontinuation and hence reduce unintended pregnancy. Women should routinely be informed about side effects during counseling and offered a possibility to switch methods if necessary during counseling. This study identified that women who didn't get pre dispensation counseling on side effects of MC were at high chance to discontinue a particular contraceptive method. Contrary to this pre dispensation counseling on side effects was not reported as predictor of modern contraceptive discontinuation [5]. This might be related to the fact that inadequate pre dispensation counseling about the main and possible side effects of MC by service providers lead to early discontinuation, as users may not be familiar what will happen related to the method and they may not ready for the solutions as well.

Findings of this study also showed that not discussing on MC with female friend increase odds of discontinuation by three fold. Consistent with this finding was reported by a study done in Agarfa district women who discussed on $\mathrm{MC}$ with their female friend decreases discontinuation by $90 \%$ as compared to were not discussed [3]. This might be because of high acceptance and trust of women for their female friends especially if they were satisfied users. The other possible reason could be in both studies, above one-third of the participants were in the age group of 25-29 years which is highly influenced by peer pressure.

Absence of husband support was found to be significantly associated with modern contraceptive discontinuation. This finding is in line with the study in Bangladesh where women who did not have their husbands' support in their OCP use had double the risk of discontinuing $\mathrm{OC}$ use than their counterparts [11] and a study in Agarfa district women who had support from their husbands to use MC decreases MCD by $85 \%$ than those who had no support from their husbands [3]. The possible reason might be the fact that husband disapproval in using contraceptive is a reason for MCD. Moreover, in these studies most of the participant's occupations were housewife and they could be economically dependent on husbands' income which in turn influences their decision.

We also found that presence of community prohibition as another predictor of contraceptive discontinuation. The proportion of contraceptive discontinuation was significantly higher among women who reported presence of negative hearsay in their community regarding contraceptives. This finding agrees with study done in Agarfa district which shows high chance of contraceptive discontinuation among women reported presence of community prohibition [3]. The possible reason for this could be wrong perception and bad rumors of community on $\mathrm{MC}$ use, they perceive that it is sinful, cause's infertility, interfere with sexual satisfaction and many others which will lead to increment in discontinuation rate.

\section{Strengths and limitations of the study}

The strength of this study was being community-based study to be more representative and using interview for data collection method which has good reliability and excludes incomplete data. However, despite its strength, the study was not without limitations, since this study was limited to married women only at the time of the study; results may not be generalized to all women in Humera town.

\section{Conclusion}

This study shows the magnitude of modern contraception discontinuation is high among reproductive age group women in Humera town. The number of desired children, number of alive male children, experience of side effects, discussion on $\mathrm{MC}$ with a female friend, counseled on side effects, husband support to use MC and presence of community prohibition from using $\mathrm{MC}$ were the predictors of modern contraception discontinuation. The health care providers should focus on pre provision counseling, partner involvement on decision making process. In addition to this great effort should be made to address community perceptions and understanding of benefit of modern contraceptives use.

\section{Abbreviations}

AOR: Adjusted odds ratio; DHS: Demographic and health surveys; IUCD: Intrauterine contraceptive device; MC: Modern contraceptive; MCD: Modern contraceptive discontinuation; OCP: Oral contraceptive pills; SPSS: Statistical package for social science

\section{Acknowledgements}

We would like to express our gratitude to Mekelle University, College of health sciences, study participants, data collectors, Humera town Health Office \& administrative office for their great contribution for the realization of this study.

\section{Funding}

Mekelle University provide the fund for this study, organize and facilitate trainings for data collection and analysis. In addition, the funding organization contributes to the overall activities of the study by continuous supervision and provision of end to end technical support for the realization of this research.

\section{Availability of data and materials}

Datasets used for this study and other supplementing materials are available from the corresponding author on reasonable request.

\section{Authors' contributions}

NB Conceptualized the study and made a substantial contribution in the design and collection of data. AY and NB involved in data analysis, report writing and manuscript preparation. $\mathrm{HH}$ and $\mathrm{AZ}$ participated in the design, data collection, review of manuscript and final approval for publication. All authors read and approve the final manuscript. 


\section{Ethics approval and consent to participate}

Permission to conduct the study obtained from Institutional Ethics Review Board (IERB) of College of Health Sciences, Mekelle University. Official cooperation letter was obtained from Tigray regional health bureau. Moreover, prior to conducting the study, purpose and objective of the study was described to the study participants and a written informed consent was obtained.

\section{Consent for publication}

Not applicable

\section{Competing interests}

The authors declare that they have no competing interests.

\section{Publisher's Note}

Springer Nature remains neutral with regard to jurisdictional claims in published maps and institutional affiliations.

\section{Author details}

'Department of Midwifery, Axum University College of Health Science, Axum, Ethiopia. ${ }^{2}$ St. Paul Millennium Medical College, Addis Ababa, Ethiopia.

${ }^{3}$ Department of Midwifery, Mekelle University College of health Sciences, Mekelle, Ethiopia.

Received: 26 February 2018 Accepted: 10 October 2018

Published online: 22 November 2018

\section{References}

1. Khan S, Mishra V, Arnold F, Abderrahim N. Contraceptive trends in developing countries. 2007.

2. Askew SCL. Contraception discontinuation: reasons, challenges and solutions. Population Council; 2015. p. 30-3.

3. Bekele T, Gebremariam A, Tura P. Factors Associated with Contraceptive Discontinuation in Agarfa District, Bale Zone, South East Ethiopia. Epidemiology (sunnyvale). 2015:5;179. https://doi.org/10.4172/2161-1165. 1000179.

4. Leite IC, Gupta N. Assessing regional differences in contraceptive discontinuation, failure and switching in Brazil. Reprod Health. 2007:4(1):6.

5. ICF CSACEa. Ethiopia demographic and health survey key indicators report Addis Ababa and Rockville: CSA and ICF; 2016. p. 13-25.

6. Central Statistical Agency. Federal Ministry of Health and ICF International. Ethiopia demographic and health survey. Addis Ababa and Calverton: Central Statistical Agency and ICF International; 2011. p. 90-108.

7. Sedgh $G$, Singh $S$, Hussain R. Intended and unintended pregnancies worldwide in 2012 and recent trends. Stud Fam Plan. 2014:45(3):301-14.

8. Sultana DN. Prevalence and factors associated with dropouts of contraceptive in rural areas of Peshawar; 2006. p. 11-25.

9. L.Tabije AET. Contraceptive discontinuation, failer and switching behavior. Macro Int Inc. 1996:18:8-14.

10. United Nations DoEaSA, Population Division. Trends in contraceptive use worldwide. 2015

11. Callahan RL, Becker $\mathrm{S}$. The reliability of calendar data for reporting contraceptive use: evidence from rural Bangladesh. Stud Fam Plan. 2012 43(3):213-22.

12. Kalayu B, Mesganaw F. Early discontinuation of implanon and its associated factors among women who ever used implanon in Ofla District, Tigray, Northern Ethiopia. Int J Pharm Sci Res. 2015;6(3):2-7.

13. Khan MA. Factors associated with oral contraceptive discontinuation in rura Bangladesh. Health Policy Plan. 2003;18(1):101-8.

14. Sarah EK, Bradley HMS, Khan S. Levels, trends, and reasons for contraceptive discontinuation. DHS analytical studies; 2009. p. 20

Ready to submit your research? Choose BMC and benefit from:

- fast, convenient online submission

- thorough peer review by experienced researchers in your field

- rapid publication on acceptance

- support for research data, including large and complex data types

- gold Open Access which fosters wider collaboration and increased citations

- maximum visibility for your research: over $100 \mathrm{M}$ website views per year

At $\mathrm{BMC}$, research is always in progress.

Learn more biomedcentral.com/submissions 